\title{
DESENVOLVIMENTO DE TESTE ERGOMÉTRICO PARA ATLETAS DEFICIENTES VISUAIS
}

\author{
*Rafaela R. Cardoso, Guilherme F. Rizatto, Fulvia B. Manchado-Gobatto, Claudio A. Gobatto.
}

\section{Resumo}

O objetivo do estudo foi propor um teste para avaliação de desempenho de atletas com deficiência visual. Para isto, foram construídas duas estruturas que demarcam o limite do percurso por meio de estímulo tátil. Para guiar o sentido da corrida destes sujeitos, duas faixas foram colocadas ao longo do trajeto. Além disto, cada estrutura possui uma caixa de som ligada a um computador com finalidade de controlar a intensidade de corrida por estímulo sonoro. Esta proposta pode ser uma opção viável de avaliação de atletas portadores de deficiência visual.

Palavras-chave: performance, deficientes visuais, esporte paralímpico.

\section{Introdução}

Ao longo do tempo, avaliações da capacidade aeróbia e anaeróbia foram produzidas para a obtenção de dados de atletas, tornando possível a realização da prescrição e periodização do treinamento. Porém, no contexto do esporte paralímpico a literatura é escassa no que diz respeito a protocolos adaptados a atletas que possuem algum tipo de deficiência. Em especial essa abordagem, no que tange aos deficientes visuais, se limita a estudos sobre a classificação do grau de deficiência dos paratletas (Gulick e Malone, 2011; Pereira et. al. 2016).

Além disso é necessária a elaboração de um protocolo de teste para deficientes visuais, de forma que estes sejam capazes de realizar sem o auxílio de um guia. Portanto o objetivo do nosso estudo foi propor um protótipo para avaliação das capacidades aeróbia e anaeróbia de atletas com deficiência visual, no qual eles possam realizar com segurança e autonomia.

\section{Resultado e Discussão}

Para adaptar o teste para deficientes visuais, construímos duas estruturas compostas por três canos de PVC de $2 \mathrm{~m}$ cada. Dois desses canos foram fixados em bases de ferro de $20 \mathrm{~kg}$ a $2 \mathrm{~m}$ de distância entre eles. O terceiro cano foi fixado de forma horizontal ao topo dos dois primeiros, unindo-os. No cano do topo, foram colocadas 11 fitas de plástico formando uma cortina com o objetivo de informar por meio de estímulo tátil o limite do percurso. Além da cortina, no cano do topo foi colocada uma caixa de som que tem como objetivo ditar o ritmo da carga selecionada para a sessão através de uma campainha. Cada caixa de som foi ligada a um computador localizado ao centro do trajeto, possuindo um interruptor de liga e desliga. Este interruptor serve para que a caixa de som da estrutura de destino do avaliado esteja ligada enquanto que a de partida esteja desligada, orientando-os. Estas caixas serão operadas manualmente pelo avaliador, que também é responsável por quantificar a duração do teste usando um cronômetro. A distância entre as estruturas foi de $20 \mathrm{~m}$. Também foram colocadas duas faixas ao longo do percurso em paralelo a $1,10 \mathrm{~m}$ de distância entre elas que teve como objetivo servir como raia para orientar a direção de corrida dos avaliados. Além disto, dois chamadores (pesquisadores assistentes) estarão localizados a $4 \mathrm{~m}$ além das cortinas, os quais deverão bater palmas quando o avaliado correr em sua direção, auxiliando na direção de corrida. O sistema completo está ilustrado na figura 1.

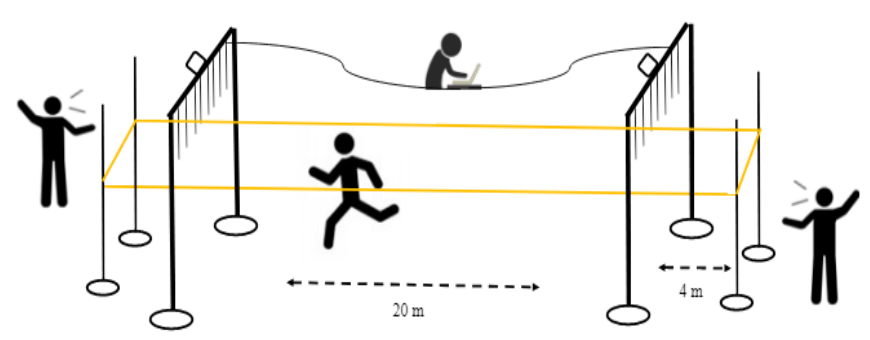

Figura 1. Percurso a ser realizado pelos atletas.

No presente momento realizamos familiarizações com quatro atletas do goalball e dois do atletismo. Ao executarem a corrida de vai-vém com carga de $8 \mathrm{~km} / \mathrm{h}$ por 2 min o protótipo apresentou-se eficiente e seguro, viabilizando a realização do exercício com autonomia, sem nenhuma intercorrência. Futuramente pretendemos submeter quatro sessões de testes de tempos superiores, com a seleção da carga de forma randomizada entre quatro pré-selecionadas. Com a seleção da carga, o avaliado terá o tempo quantificado para realizar a corrida até atingir a exaustão ou não conseguir chegar no final do percurso quando a campainha tocar por duas vezes seguidas. Para a validação da sessão será necessário que a duração total ocorra entre 2 e $10 \mathrm{~min}$, conforme preconiza o modelo de velocidade crítica (Monod e Scherrer, 1965).

\section{Conclusões}

Nosso protótipo foi capaz de fazer com que os atletas corressem de forma autônoma e segura. Portanto esse método pode ser uma forma eficaz de mensurar as capacidades aeróbia e anaeróbia de deficientes visuais.

\section{Agradecimentos}

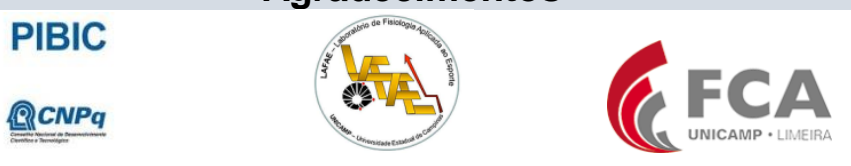

Gulick, D.T.; Malone, L.A. Int. J.Athl. Ther. Train. 2011, 16, 22-25 Pereira L, Winckler C, Abad CC, Kobal R, Kitamura K, Veríssimo A, Nakamura FY, Loturco I. Adapt Phys Activ Q. 2016, 33(4), 311-323 Monod H, Scherrer J. Ergonomics. 1965; 8(3), 329-38. 